\title{
Massive Gastrointestinal Bleeding Due to Jejunal Diverticula in a Community Hospital: A Case Report and Review of Diagnostic and Therapeutic Options
}

\author{
Cynthia Abbasi ${ }^{1, *,+}+\mathbb{D}$, M. Carolina Jimenez ${ }^{2, *,+}+\mathbb{D}$ and Michael Lisi ${ }^{2,3,4}$ \\ 1 Townsville University Hospital, Douglas, QLD 4814, Australia \\ 2 Division of General Surgery, University of Toronto, Toronto, ON M5S 1A1, Canada; lisimp@mcmaster.ca \\ 3 Department of surgery, McMaster University, Hamilton, ON L8S 4L8, Canada \\ 4 Department of surgery, Queens University, Kingston, ON K7L 3N6, Canada \\ * Correspondence: cynthia.abbasi@health.qld.gov.au (C.A.); mcarolina.jimenez@one-mail.on.co (M.C.J.) \\ + These authors contributed equally to the paper.
}

Citation: Abbasi, C.; Jimenez, M.C.; Lisi, M. Massive Gastrointestinal Bleeding Due to Jejunal Diverticula in a Community Hospital: A Case Report and Review of Diagnostic and Therapeutic Options. Gastroenterol. Insights 2021, 12, 196-201. https:// doi.org/10.3390/gastroent12020017

Academic Editor: Gaetano Luglio

Received: 4 March 2021

Accepted: 12 April 2021

Published: 21 April 2021

Publisher's Note: MDPI stays neutral with regard to jurisdictional claims in published maps and institutional affiliations.

Copyright: (c) 2021 by the authors. Licensee MDPI, Basel, Switzerland. This article is an open access article distributed under the terms and conditions of the Creative Commons Attribution (CC BY) license (https:// creativecommons.org/licenses/by/ $4.0 /)$.

\begin{abstract}
Small bowel diverticula are rare and often asymptomatic. Severe lower gastrointestinal bleeding from jejunal diverticula is rarely reported and, therefore, should be considered a differential diagnosis in all cases of lower gastrointestinal bleeding with nonconclusive gastroscopy and colonoscopy. In this case report, we discuss a case of a 75-year-old male with massive lower gastrointestinal bleeding from jejunal diverticula. Initial gastroscopy did not reveal the source of bleeding. Repeat upper endoscopy with a pediatric colonoscope identified jejunal diverticula as the likely source of bleeding. Angiography identified the site of extravasation, and successful angioembolization was done by interventional radiology.
\end{abstract}

Keywords: diverticulosis; diverticulitis; jejunum; computed tomography; endoscopy; pediatric colon scope; surgery

\section{Introduction}

Acute gastrointestinal bleeding is a medical emergency that contributes to the patient's morbidity and mortality [1]. Severe gastrointestinal bleeding secondary to small bowel diverticula is rare. More specifically, bleeding due to jejunal diverticula is even rarer and accounts for up to 2.3 percent of individuals in radiographic series and 7 percent in autopsy studies $[2,3]$. The majority of patients with jejunal diverticulosis are asymptomatic. However, patients can present with complications such as bleeding, perforation or abscess. Due to difficulty accessing the small bowel via endoscopy, establishing a diagnosis can be delayed. In this case report, we discuss a case of a 75-year-old man with massive lower gastrointestinal bleeding from jejunal diverticula and highlight the diagnostic evaluations and treatment involved.

\section{Case Report}

A 75-year-old man, previously well, was transported to our community hospital after sustaining a fall at home, caused by a sudden episode of large frank blood per rectum and syncopal event. During the initial assessment in the emergency department, he was somewhat agitated. He denied any previous symptoms. He was hemodynamically stable, and the abdomen was nontender. Digital rectal examination revealed large hemorrhoids and bright red blood in the rectum. He had superficial lacerations in the anterior and posterior scalp. He did not have signs of neurological focalization. Initial hemoglobin was $106 \mathrm{~g} / \mathrm{L}$, and there was no evidence of coagulopathy. CT scan of the head demonstrated a small subdural hematoma and lacerations to the anterior and posterior scalp. No abdominal imaging was done up to this point. 
His past medical history included duodenal ulcer, coronary artery disease with triple bypass, hypertension, dyslipidemia, gastroesophageal reflux disease, and benign prostatic hyperplasia. He was on ASA $81 \mathrm{mg}$ daily and was not taking any other anticoagulant or antiplatelet agents.

He was admitted to the intensive care unit (ICU), where he experienced another fall and another episode of large bright red blood per rectum. He remained hemodynamically stable, with a nontender abdomen and, up to this point, did not require blood products. A gastroscopy was performed, but no source of bleeding was identified. The patient stabilized, and bowel preparation was started for a colonoscopy. That evening, he became tachycardic and had further frank red blood per rectum mixed with melena stool. A massive transfusion protocol was activated, and he received 7 units of packed red cells and tranexamic acid.

A colonoscopy was performed and demonstrated some blood in the colon and distal ileum, but the source was not identified. A pediatric colonoscope was used for repeat upper endoscopy in order to advance further down into the small bowel. At 60-70 cm from the incisions, a diverticulum was seen in the jejunum, with surrounding bright blood, but the exact source could not be identified. Differential diagnosis included bleeding diverticula, dysplastic lesion or neoplasm. During endoscopy, he responded to blood products, and vital signs stabilized. A triphasic CT of the abdomen was done and confirmed active extravasation in the small bowel around the mid jejunum (Figure 1). A repeat head CT scan demonstrated a stable subdural hematoma.

(A)

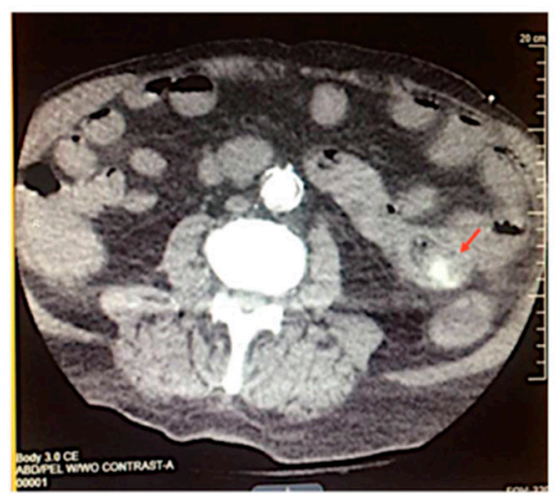

(B)

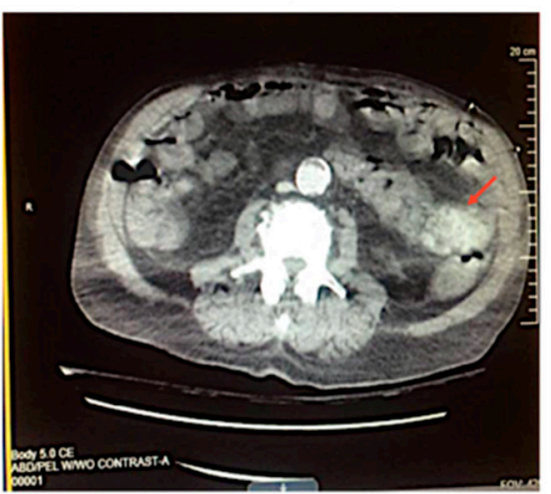

Figure 1. CT angiogram. Transverse CT sections of arterial phase axial series (A) and portal venous phase (B) reveal active contrast extravasation in a segment of small bowel in the left hemiabdomen, around the region of mid jejunum, in keeping with active small bowel bleeding. The red arrow in Figure $1 \mathrm{~A}, \mathrm{~B}$ is pointing towards the active contrast extravasation.

He was transferred to a nearby hospital for angioembolization by interventional radiology. En route, he began to bleed again and became hemodynamically unstable. Blood transfusion was restarted, but he responded only partially to treatment and remained unstable. Upon arrival to the nearby hospital, angiography was performed immediately, revealing extravasation from a straight jejunal artery (Figure 2). He underwent successful angioembolization with microcoils and was transferred to the ICU, where he had an uneventful recovery without the need for further blood products. This case report sheds light on the importance of general surgeons in community hospitals managing gastrointestinal bleeding and having an understanding of algorithms for management. 
(A)

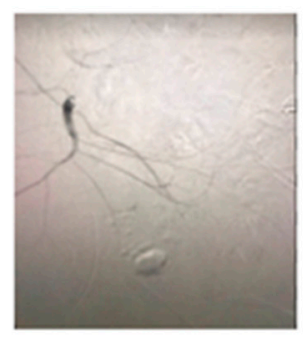

(B)

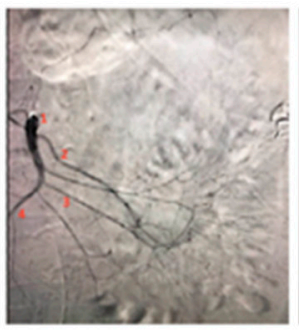

1 - proximal SMA

2- Jejunal branches

4- Distalterminal SMA
(C)

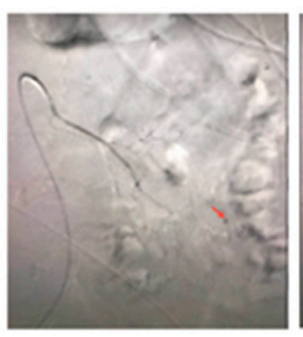

(D)

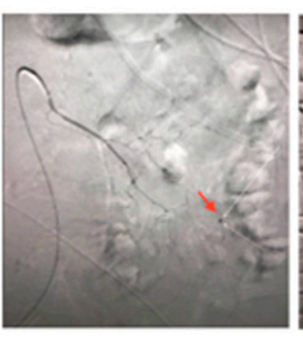

(E)

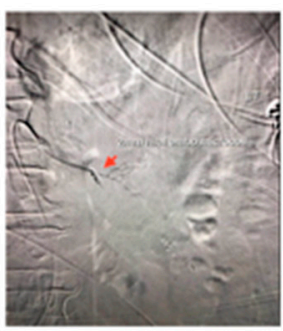

Figure 2. Angiography. (A,B) illustrates jejunal artery and its branches labeled. Angiography revealed extravasation from a straight jejunal artery, shown by the red arrow (C,D). Selective microcatheterization of the involved vas rectum was performed (D). Embolization with microcoils led to the occlusion of the ruptured vas rectum, and hemostasis was achieved as shown by the red arrow (E).

\section{Discussion}

Small intestinal diverticula usually occur on the mesenteric side of the bowel, where increased intraluminal pressure leads to the protrusion of mucosa through defects in the lamina muscularis [4-7]. Small intestinal diverticula are far less common compared to colon diverticula [4-7]. Jejunal diverticula are often asymptomatic, but symptomatic cases can be associated with a number of complications, including stasis and bacterial overgrowth, diarrhea, malabsorption, intestinal pseudo-obstruction, gastrointestinal bleeding, diverticulitis, and, rarely, free perforation with peritonitis [5].

Symptomatic jejunal diverticula can mimic other conditions, and diagnosis tends to be delayed [8-13]. Gastrointestinal bleeding is a common presentation of complicated jejunal diverticula. Patients presenting with suspected gastrointestinal bleeding require upper and lower scopes after appropriate resuscitation [14-17]. As per the Practice Guidelines for Emergency General Surgery of the Canadian Association of General Surgeons, upper and lower scopes are often first-line diagnostic and therapeutic modalities for upper and lower gastrointestinal bleeding. They allow direct visualization of the mucosa and can identify the source of bleeding, hence allowing the application of hemostatic therapy and tissue sampling if there is suspected malignancy. If the source is not identified post upper and lower scopes, CT enterography needs to be initiated to look for small bowel bleeds [18]. Current treatments for jejunal diverticula include endoscopic therapy, transcatheter arterial embolization or surgery [19-22].

Although endoscopic visualization of the small bowel is limited by colonoscopy and gastroscopy, advances in endoscopy, with the introduction of push endoscopy and capsule endoscopy, have allowed for visualization of the entire small bowel [14-17]. Enteroscopy of the small bowel can be divided into push enteroscopy and device-assisted deep enteroscopy [23]. Push enteroscopy permits evaluation of the proximal small intestine to a distance that is approximately 50 to $100 \mathrm{~cm}$ beyond the ligament of Treitz [24]. Dedicated enteroscopes have an approximate length of $250 \mathrm{~cm}$ but are not available in all hospitals [24]. Colonoscopy is a well-recognized alternative, allowing a distance of insertion 40 to $50 \mathrm{~cm}$ beyond the ligament of Treitz, although its rigidity and calibre can prevent it from advancing smoothly in the jejunum [24]. An interim solution can be found in the pediatric colonoscope, which has greater shaft flexibility, a smaller insertion tube diameter than an adult colonoscopy, and a working channel that is suitable for administration [14-17]. Localization of stigmata of hemorrhage at a diverticulum requires careful endoscopic visualization, and assistance with a water jet can be useful. The use of a clear plastic cap along with gentle suction can also aid in inverting the diverticulum to visualize stigmata present at the dome of a diverticulum [25-30]. 
Available techniques for endoscopic hemostasis include dilute epinephrine injection, bipolar electrocoagulation, through-the-scope clipping, endoscopic band ligation, and the use of over-the-scope clips [28]. However, the optimal strategy for endoscopic hemostasis has yet to be defined and is largely dependent on operator preference and experience [28].

$\mathrm{CT}$ angiography (CTA) is done for patients with lower GI bleeding who are stable and patients who have lower and upper GI bleeding with no source identified [10,22,31,32]. CTA has a sensitivity of $85.2 \%$ and specificity of $92.1 \%$ for detecting intestinal bleeding [10]. It is important to consider CTA as an initial diagnostic test for hemodynamically stable patients who are waiting for endoscopy. In our case, we had immediate access to an endoscopy suite, and, hence, our patient was able to have lower and upper scopes done as per guidelines, prior to CTA being performed. CTA can accurately identify the source of arterial and venous gastrointestinal bleeding, diagnose the underlying cause and direct further management [31-33]. The disadvantages of CTA are high radiation dose, need for IV contrast, and false-negative results, which can occur if the patient is not actively bleeding at the time of the scan [31-33].

A tagged RBC scan can be considered if there is significant renal dysfunction [28]. Angiography with a view of embolization should be performed after a positive CTA to increase the chance of ceasing the bleeding. A retrospective review of 48 cases with positive CTA scans illustrated that angiograms done within $90 \mathrm{~min}$ of a positive CTA scan were 8 times more likely to identify active bleeding [18]. Data on the specific timing to angiography following a positive CTA or red cell scan are limited to small retrospective studies [18].

Of the small group of patients that fail to respond to endoscopic therapy, some are treated surgically, but, increasingly, the majority are referred for angioembolization [18]. Angiography is most often performed as a precursor to transcatheter arterial embolization (TAE). A positive examination is classically described as extravasation of contrast into the bowel lumen or false aneurysm-like lesions [29]. If extravasation is demonstrated in angiography, embolization can be undertaken, although there are no direct head-to-head trials or retrospective studies of embolization versus endoscopic therapy. Embolization can be performed using coils, liquid agents or particles $[29,33]$. The principal agents used are platinum coils, N-butyl cyanoacrylate and polyvinyl alcohol particles [33]. TAE has shown to be effective at controlling hemorrhage and decreasing mortality [29].

The technical success rates of embolization are high, reported at $69-100 \%$, regardless of the embolic agent being used [33]. Bowel ischemia is the most commonly reported major complication, with an incidence of 7-33\% [33]. The risk of rebleeding in the short term after embolization varies from $10 \%$ to $50 \%[15,21-24]$. However, due to advancements in microcatheter technology, the incidence of bowel ischemia has decreased significantly [24]. Thus, TAE should be considered a primary treatment for life-threatening lower gastrointestinal bleeding [21].

Teng et al. demonstrated an $11.5 \%$ rate of surgical intervention after failed embolization. The study also reported an overall survival rate of $58 \%$ and $43 \%$ at 1 and 5 years after embolization [25]. Indication for surgery includes life-threatening bleeding in patients who fail endoscopy and embolization treatment [19-21]. Surgery is often the last option due to higher rates of morbidity and mortality [19-21]. Proceeding to laparotomy without localization of the source of the bleeding can be particularly challenging [33]. Therefore, localization of the bleeding lesion before surgical resection is critical to preventing recurrent bleeding after surgery, owing to a missed or incorrectly localized lesion [26]. Surgery may also be indicated in the management of complications of endoscopic or radiological interventions [33].

In our case, upper and lower endoscopies were the initial evaluations in diagnosis. A pediatric colonoscope was essential, in this case, to advance further down into the small bowel and visualize the area where the bleeding appeared to originate. A CTA confirmed active bleeding, which followed mesenteric angiography. Studies have shown that the microcoils used in our patient have an $88.6 \%$ technical success rate and a $56.8 \%$ clinical success rate [26]. 


\section{Conclusions}

Jejunal diverticula are rare, and the diagnosis of symptomatic cases tends to be delayed due to presentation with vague symptoms. Therefore, it is important to consider jejunal diverticula as a differential diagnosis of acute gastrointestinal bleeding as it can lead to life-threatening complications and death.

In case of acute gastrointestinal bleeding, the aim is to determine the site and severity of bleeding, provide supportive measures and initiate resuscitation if the patient is unstable [33-35]. Following this, additional investigations need to be initiated to find the source of bleeding and initiate therapy [33-35]. Once the patient is hemodynamically stable, upper and lower scopes need to be initiated. Endoscopy is a first-line diagnostic and therapeutic study in patients with acute GI bleeding. Endoscopy is highly sensitive and specific for upper GI bleeding [33-35]. Following endoscopy, if the source of bleeding is not identified and the patient remains stable, colonoscopy must be performed [33-35]. Endoscopy and colonoscopy allow for the visualization of mucosa; thus, the source of bleeding can be visualized, and hemostatic therapy can be applied. However, endoscopy and colonoscopy have a number of limitations [33-35]. For instance, it may be extremely difficult and impossible to identify the source of bleeding in individuals with a large volume of bleeding. Additionally, endoscopy and colonoscopy are limited to visualizing the small bowel distal to the ligament of Treitz. Advances in endoscopy, with the introduction of double-balloon or single-balloon endoscopy, allow for the visualization of the entire small bowel [14]. However, in rural areas, where double-balloon or single-balloon endoscopy is not available, a solution can be found by using a pediatric colonoscope [14-17,34,35].

Following endoscopy and colonoscopy, CTA should be initiated if doctors are unable to visualize the source of bleeding [33,35]. CTA is being increasingly used for the diagnosis of acute gastrointestinal bleeding since it can be done rapidly and is universally available in acute settings $[10,33,35]$. After identification of the source of bleeding, interventional embolization can be used initially as a minimally invasive method to embolize jejunal hemorrhage.

Author Contributions: C.A., M.C.J. and M.L. contributed equally to this case report. All authors have read and agreed to the published version of the manuscript.

Funding: This research received no external funding.

Institutional Review Board Statement: Not applicable.

Informed Consent Statement: Not applicable.

Conflicts of Interest: The authors declare no conflict of interest.

\section{References}

1. Carney, B.; Khatri, G.; Shenoy-Bhangle, A. The role of imaging in gastrointestinal bleed. Cardiovasc. Diagn. Ther. 2019, 9, S88-S96. [CrossRef] [PubMed]

2. De Peuter, B.; Box, I.; Vanheste, R.; Dymarkowski, S. Small-bowel Diverticulosis: Imaging Findings and Review of Three Cases. Gastroenterol. Res. Pract. 2009, 1-3. [CrossRef] [PubMed]

3. Lebert, P.; Millet, I.; Ernst, O.; Boulay-Coletta, I.; Corno, L.; Taourel, P.; Zins, M. Acute Jejunoileal Diverticulitis: Multicenter Descriptive Study of 33 Patients. Am. J. Roentgenol. 2018, 210, 1245-1251. [CrossRef]

4. Harbi, H.; Kardoun, N.; Fendri, S.; Dammak, N.; Toumi, N.; Guirat, A.; Mzali, R. Jejunal diverticulitis. Review and treatment algorithm. Presse Médicale 2017, 46, 1139-1143. [CrossRef]

5. Leigh, N.; Sullivan, B.; Anteby, R.; Talbert, S. Perforated jejunal diverticulitis: A rare but important differential in the acute abdomen. Surg. Case Rep. 2020, 6, 1-7. [CrossRef] [PubMed]

6. Andersen, L.; Schjoldager, B.; Halver, B.J. Jejunal Diverticulosis in a Family. Scand. J. Gastroenterol. 1988, 23, 672-674. [CrossRef] [PubMed]

7. Almaramhy, H. Jejunal atresia associated with jejunal diverticulosis. J. Pediatric Surg. Case Rep. 2018, 32, 68-71. [CrossRef]

8. Yaqub, S.; Evensen, B.; Kjellevold, K. Massive rectal bleeding from acquired jejunal diverticula. World J. Emerg. Surg. 2011, 6, 17. [CrossRef]

9. Cherian, M.; Mehta, P.; Kalyanpur, T.; Hedgire, S.S.; Narsinghpura, K.S. Arterial Interventions in Gastrointestinal Bleeding. Semin. Interv. Radiol. 2009, 26, 184-196. [CrossRef] 
10. Reis, F.; Cardia, P.; D'Ippolito, G. Computed tomography angiography in patients with active gastrointestinal bleeding. Radiol. Bras. 2015, 48, 381-390. [CrossRef]

11. Wong, C.; Lin, I.; Shih, S.; Chang, W.H.; Wang, H.Y. Jejunal Diverticula Causing Unusual Massive Lower Gastrointestinal Bleeding. Int. J. Gerontol. 2008, 2, 120-123. [CrossRef]

12. Mohan, P.; Manov, J.; Diaz-Bode, A.; Venkat, S.; Langston, M.; Naidu, A.; Howse, R.; Narayanan, G. Clinical Predictors of Arterial Extravasation, Rebleedingand Mortality Following Angiographic Interventions in Gastrointestinal Bleeding. J. Gastrointest. Liver Dis. 2018, 27, 221-226. [CrossRef] [PubMed]

13. Mensel, B.; Kühn, J.; Kraft, M.; Rosenberg, C.; Partecke, L.I.; Hosten, N.; Puls, R. Selective microcoil embolization of arterial gastrointestinal bleeding in the acute situation. Eur. J. Gastroenterol. Hepatol. 2012, 24, 155-163. [CrossRef]

14. Kim, B. Diagnosis of gastrointestinal bleeding: A practical guide for clinicians. World J. Gastrointest. Pathophysiol. 2014, 5, 467. [CrossRef] [PubMed]

15. Bond, A.; Smith, P. British Society of Gastroenterology: Diagnosis and management of acute lower gastrointestinal bleeding. Frontline Gastroenterol. 2019, 10, 417-420. [CrossRef]

16. Pérez Roldán, F.; González Carro, P.; Legaz, H.M.L.; Roncero García-Escribano, O.; Ynfante Ferrús, M.; Aoufi, S.; Sánchez-Manjavacas Muñoz, N.; Ruiz Carrillo, F. Efficacy of pediatric colonoscopy used as push enteroscopy in the management of capsule endoscopy findings. Rev. Española de Enferm. Dig. 2009, 101, 468-476. [CrossRef]

17. Zhou, D.; Jiang, B.; Yang, X. Advances and applications of enteroscopy for small bowel. World J. Gastroenterol. 1997, 3, 205. [CrossRef]

18. Zhao, L.; Lu, W.; Sun, Y.; Liang, J.; Feng, S.; Shi, Y.; Wu, Q.; Wang, J.; Wu, K. Small intestinal diverticulum with bleeding. Medicine 2018, 97, e9871.

19. Abegunde, A.; Christman, E.; Hassell, L.; Kastens, D. Rare Jejunal Diverticular Bleeding. ACG Case Rep. J. 2016, 3, e146. [CrossRef]

20. Mantas, D. Small intestine diverticula: Is there anything new? World J. Gastrointest. Surg. 2011, 3, 49. [CrossRef]

21. Tarasconi, A.; Baiocchi, G.; Pattonieri, V.; Perrone, G.; Abongwa, H.K.; Molfino, S.; Portolani, N.; Sartelli, M.; di Saverio, S.; Heyer, A.; et al. Transcatheter arterial embolization versus surgery for refractory non-variceal upper gastrointestinal bleeding: A meta-analysis. World J. Emerg. Surg. 2019, 14, 1-13. [CrossRef] [PubMed]

22. Wortman, J.; Landman, W.; Fulwadhva, U.; Viscomi, S.G.; Sodickson, A.D. CT angiography for acute gastrointestinal bleeding: What the radiologist needs to know. Br. J. Radiol. 2017, 90, 20170076. [CrossRef]

23. Levy, I.; Gralnek, I. Complications of diagnostic colonoscopy, upper endoscopy, and enteroscopy. Best Pract. Res. Clin. Gastroenterol. 2016, 30, 705-718. [CrossRef]

24. Maza, I.; Gralneck, I.M. Chapter 15-Obscure Gasrointestinal Bleeding. In Clinical Gastrointestinal Endoscopy, 2nd ed.; Elsevier Inc.: Amsterdam, The Netherlands, 2012; pp. 173-179.

25. Teng, H.C.; Liang, H.L.; Lin, Y.H.; Huang, J.S.; Chen, C.Y.; Lee, S.C.; Pan, H.B. The Efficacy and Long-Term Outcome of Microcoil Embolotherapy for Acute Lower Gastrointestinal Bleeding. Korean J. Radiol. 2013, 14, 259. [CrossRef] [PubMed]

26. Ul-Haq, T.; Idris, M.; Salam, B.; Akhtar, W.; Jamil, Y. Comparison of microcoils and polyvinyl alcohol particles in selective microcatheter angioembolization of non-variceal acute gastrointestinal hemorrhage. Park J. Med. Sci. 2015, 31, 751-756.

27. Gralnek, L.M.; Neeman, Z.; Strate, L.L. Acute Lower Gastrointestinal Bleeding. N. Engl. J. Med. 2017, 376, 1054-1063. [CrossRef]

28. Sengupta, N. The role of colonoscopy and endotherapy in the management of lower gastrointestinal bleeding. Best Pract. Res. Clin. Gastroenterol. 2019, 42-43, 101615. [CrossRef] [PubMed]

29. Loffroy, R.; Rao, P.; Ota, S.; de Lin, M.; Kwak, B.-K.; Geschwind, J.-F. Embolization of Acute Nonvariceal Upper Gastrointestinal Hemorrhage Resistant to Endoscopic Treatment: Results and Predictors of Recurrent Bleeding. Cardiovasc. Interv. Radiol. 2010, 33, 1088-1100. [CrossRef]

30. Soetikno, R.; Ishii, N.; Kolb, J.; Hammad, H.; Kaltenbach, T. The Role of Endoscopic Hemostasis Therapy in Acute Lower Gastrointestinal Hemorrhage. Gastrointest. Endosc. Clin. N. Am. 2018, 28, 391-408. [CrossRef] [PubMed]

31. Feuerstein, J.D.; Ketwaroo, G.; Tewani, S.K.; Cheesman, A.; Trivella, J.; Raptopoulos, V.; Leffler, D.A. Localizing Acute Lower Gastrointestinal Hemorrhage: CT Angiography Versus Tagged RBC Scintigraphy. Gastroinetstinal Imaging 2016, 207, 578-584. [CrossRef]

32. Artigas, J.M.; Marti, M.; Soto, J.A.; Esteban, H.; Pinilla, I.; Guillen, E. Multidetector CT Angiography for Acute Gastrointestinal Bleeding: Technique and Findings. Trauma Emerg. Radiol. 2013, 33, 1453-1470.

33. Oakland, K.; Chadwick, G.; East, J.; Guy, R.; Humphries, A.; Jairath, V.; McPherson, S.; Metzner, M.; Morris, A.J.; Murphy, M.F.; et al. Diagnosis and management of acute lower gastrointestinal bleeding: Guidelines from the British Society of Gastroenterology. Gut 2019, 68, 776-789. [CrossRef]

34. Trindade, A.; Lichtenstein, D.; Aslanian, H.; Bhutani, M.S.; Goodman, A.; Melson, J.; Navaneethan, U.; Pannala, R.; Parsi, M.A.; Sethi, A.; et al. Devices and methods to improve colonoscopy completion (with videos). Gastrointest. Endosc. 2018, 87, 625-634. [CrossRef] [PubMed]

35. Strate, L.; Gralnek, I. ACG clinical guideline: Management of patients with acute lower gastrointestinal bleeding. Am. J. Gastroenterol. 2016, 111, 459-474. [CrossRef] [PubMed] 